\title{
ARTIGO
}

\section{Informação empresarial: dos sistemas transacionais à latência zero}

\author{
Company information: from electronic \\ transaction systems to zero latency
}

Orandi Mina FALSARELLA ${ }^{1}$

Celeste Aída Sirotheau Corrêa JANNUZZI ${ }^{1}$

Vera Sílvia Marão BERAQUET ${ }^{1}$

\section{RE S U M O}

De cunho teórico e conceitual, o texto discorre sobre o uso das Tecnologias de Informação nas empresas em geral. Apresenta os conceitos básicos atribuídos à informação nesse ambiente e discorre sobre os diversos tipos de sistemas computadorizados de informações, disponíveis atualmente para as empresas. Discute o conceito de Latência Zero que, por meio de indicadores, contribui para o monitoramento do ambiente nas organizações, permitindo melhorar o tempo entre a ocorrência de um determinado evento e a tomada de decisão.

Palavras-chave: informação, empresa, tecnologia de informação, sistema de informação, monitoramento, ambiente de observação.

\section{A B S T R A C T}

This text, which has a theoretical and conceptual character, considers the use of the Information Technologies within companies in general. It presents the basic concepts attributed to information within such environment, as well as the diverse types of computerized information systems currently available for companies. It

\footnotetext{
1 Professores, Programa de Pós-Graduação em Ciência da Informação, Pontifícia Universidade Católica de Campinas. Praça Imaculada, 105, Vila Santa O dila, 13045-901, Campinas, SP, Brasil. Correspondência para/C orrespondence to: O.M. Falsarella. E-mail: orandi@puc-campinas.edu.br
} 
discusses the concept of Zero Latency which, by means of indicators, contributes to the organizations' environment monitoring, improving the time between the occurrence of an event and the decision-making.

Key words: information, company, information technology, information system, monitoring, observation environment.

\section{N T R O D U Ç Ã O}

Até os anos 1800, a sociedade não tinha a idéia de empresa da forma como hoje é compreendida. Somente a partir da Revolução Industrial, principalmente no século XIX, com o surgimento das máquinas, da produção em série, da classe operária etc., é que se começa a conceber a empresa nos moldes atualmente definidos.

As invenções e inovações trazidas pela Revolução Industrial promovem mudanças na configuração das empresas e as máquinas passam a fazer parte dessa nova realidade. Nesse contexto, observa-se, com ênfase na Europa e nos Estados Unidos, a proliferação das empresas industriais que se devotam em organizar seu ambiente interno para que possam produzir cada vez mais. Essa mentalidade, com o foco na produção em massa, no qual o preço é o fator de diferenciação dos produtos, vai sendo consolidada até a primeira metade do século $X X$ (ANSOFF; McDONELL, 1993).

A partir de 1930, com a crise da depressão enfrentada com a quebra da Bolsa de New York, as empresas passam a enfrentar uma nova situação no mercado, levando-as a buscar um novo foco de atuação - o da diferenciação. Este novo contexto contribui para que as empresas busquem novas características para seus produtos, bem como novas formas de posicionamento no mercado, e ganhe maiores reforços com os avanços tecnológicos obtidos a partir da Segunda Guerra Mundial.

Desse modo, em um cenário mais competitivo, a novidade e a rapidez nas respostas às necessidades do mercado tornam-se fatores determinantes para a sobrevivência das organizações. Dentro destas proposições, a informação passa a ser o recurso estratégico para que essas instituições possam conhecer seus concorrentes, seus fornecedores, seu mercado consumidor etc., a fim de desenvolver sua estratégia competitiva (PORTER, 1991).

Assim, com o volume crescente de informações, de caráter científico, tecnológico e de negócios, as instituições passam a buscar meios que favoreçam a coleta, sistematização e disponibilização dessas informações a fim de subsidiar seu processo decisório contribuindo para sua permanência no mercado.

Dessa forma, após a Segunda Guerra Mundial que culminou com uma grande capacidade produtiva das indústrias e um enorme volume de conhecimentos oriundos das inovações tecnológicas, as informações necessitavam ser disponibilizadas de forma mais eficiente. Neste contexto, principalmente na segunda metade do século $X X$, as instituições vêem-se beneficiadas com o surgimento de duas novas áreas do conhecimento: a Informática e a Ciência da Informação.

A informática, cujo termo representa a conjunção de informação automática, é uma ciência que visa o tratamento da informação de forma racional através do uso de recursos, como máquinas automáticas (hardware) providas de instruções para a execução de tarefas de processamento de dados (software), considerados como suportes à comunicação e ao conhecimento humano (MEIRELLES, 1994). 
A Ciência da Informação, por sua vez, é o campo do conhecimento que, segundo Barreto (2002, p.70), "estuda a ação mediadora entre informação e conhecimento acontecido no indivíduo", ou seja, a Ciência da Informação estuda a informação no contexto de um fluxo, caracterizado desde a produção (geração) da informação, organização, distribuição (em diferentes tipos de suporte) até a recepção e utilização da informação.

Assim, no contexto do século XX e início do século XXI, observa-se que

O mundo assiste ao desabrochar de um ciclo de evolução/revolução do conhecimento científico, baseado na biologia, na microeletrônica, na Informática, na teoria de sistemas, nos novos materiais e nas ciências da comunicação e da informação, onde não só os modos de produção e consumo estão sendo modificados, como também as mentalidades e as práticas sociais e humanas estão mudando e transformando-se (MEIRELLES, 1994, p.16).

A afirmação do autor é uma realidade e a informação apresenta-se como o recurso necessário para proporcionar essas mudanças. O avanço tecnológico que está ocorrendo atualmente nas Áreas de Telecomunicações e de Informática e com o crescimento do número de instituições que se utilizam dessas tecnologias, novas aplicações - denominadas neste trabalho de Tecnologias de Informação (TI) - estão surgindo e modificando o modo de agir das instituições, de seus funcionários e de seus clientes, permitindo que o compartilhamento das informações transponha os obstáculos relacionados ao tempo e ao espaço.

Com o uso dessas novas $\mathrm{TI}$, as empresas podem agregar funcionários de instituições distintas, usar recursos físicos dispersos geograficamente e integrar sistemas de informações antes totalmente independentes. As TI estão sendo inseridas na estrutura das instituições para otimizar procedimentos administrativos e automatizar a produção e/ou a prestação de serviços, causando mudanças radicais, com efeitos que podem gerar alterações imediatas nas estruturas organizacionais.

Se por um lado as TI vêm evoluindo rapidamente causando mudanças, por outro, as empresas têm necessidade de se reestruturarem para aumentar a competitividade e enfrentar a concorrência. Sendo assim, para atender à crescente demanda por posições no mercado é necessário que as instituições estejam organizadas, capacitadas e abertas para mudanças. Nesse sentido, é essencial que elas se preocupem constantemente em: manter-se permanentemente atualizadas quanto às $\mathrm{TI}$ disponíveis no mercado; buscar Tl emergentes e analisar o impacto da sua utilização pela organização; analisar TI quanto à sua aplicabilidade, tanto no que se refere aos aspectos técnicos, quanto no que concerne aos aspectos mercadológicos; adaptar as TI existentes às necessidades específicas da instituição no sentido de buscar competitividade; buscar o aprimoramento de soluções, de modo a atender à evolução das necessidades estratégicas da instituição.

As TI, aliadas aos métodos de coleta, tratamento e transferência de informações estudados na Ciência da Informação, permitem que a instituição agilize o tratamento dos dados, bem como a disponibilização das informações, tornando eficiente a gestão da informação. Dentro desse cenário, torna-se importante que as instituições utilizem a TI para poder competir e enfrentar a concorrência e, não menos importante, ter condições de absorvê-la adequadamente.

\section{O RG A N IZAÇÃ O E N ÍVEIS DE A D M I N ISTRAÇ Ã O}

As organizações são objetos de estudo, em primeiro lugar, pela importância que elas 
ocupam na vida dos indivíduos, ou seja, desde o nascimento o ser humano vive em algum tipo de organização, (por exemplo, familiar, religiosa, esportiva, trabalhista, previdenciária); e, em segundo lugar, pela velocidade com que elas se transformam, influenciando e modificando o modo de vida das pessoas (MACEDO, 1999).

Uma organização é uma instituição ou uma associação que tem objetivos claros e bem definidos. Ela é constituída por pessoas que possuem atribuições individuais, que combinadas de modo estruturado com outros tipos de elementos (por exemplo, outras pessoas, tempo, espaço, materiais e informação), têm como finalidade realizar propósitos coletivos (MAXIMIANO, 1995).

Hampton (1981, p.7) define organização como " uma combinação intencional de pessoas e tecnologia para atingir um determinado objetivo" e destaca que o ponto fundamental de uma organização é existir dentro de um ambiente que envolve clientes, fornecedores e concorrentes, além de condições legais, econômicas, sociais e tecnológicas para sobreviver.

O conceito de sistema, "um conjunto de processos interrelacionados que funcionam ou devem funcionar harmoniosamente, usando vários recursos (insumos), de modo a atingir objetivos pré-estabelecidos (produtos)" (KARAPETROVIC, 1999), pode também ser aplicado ao conceito de organização.

Segundo Bresciani Filho e D'Ottaviano (2000), dentro de um sistema, cada elemento possui uma identidade que o caracteriza e o distingue dos demais elementos. O estado de cada elemento é representado por parâmetros que contém valores variáveis ou constantes, que expressam as propriedades, atributos, predicados e qualidades do elemento. Os valores que cada elemento possui são expressos pelas suas próprias características, pela sua relação com outros elementos e pelas restrições externas que cada um deles possui. A organização entre os elementos de um sistema é uma característica essencial para o seu funcionamento e a forma com que a organização deles é feita, define a estrutura do sistema.

O sistema organização, se assim for denominado, coleta recursos financeiros, humanos, materiais e tecnológicos do meio em que atua, modifica esses recursos através de algum processo de transformação e gera produtos e serviços, objetivo-fim de uma organização (MAIA; SOUZA, 1999).

Dentro de uma organização existem elementos distintos com identidades próprias que se relacionam entre si. Os insumos podem ser representados pela matéria-prima ou pelos conhecimentos existentes, que serão utilizados em organizações prestadoras de serviços. Os objetivos finais da organização podem ser expressos pelos produtos criados e comercializados ou pelos serviços prestados. O processo, que transforma insumos em produtos ou serviços, é representado pelo relacionamento existente entre as entidades distintas (recursos humanos, local físico, informação e recursos financeiros) estruturadas e administradas pelo elemento gerência que contribui para a organização dos elementos do sistema. Essas atividades, após serem organizadas, são distribuídas para as pessoas ou grupo de pessoas que irão executá-las. Essas pessoas, ou grupo de pessoas, estão, normalmente, alocadas dentro de uma estrutura organizacional.

Uma estrutura organizacional, portanto, pode ser definida como a forma pela qual as atividades de uma organização são divididas, ou seja, como as tarefas mais complexas podem ser decompostas em componentes de modo que indivíduos ou grupos de pessoas tenham condições de realizá-las; organizadas no sentido de que possam ser agrupadas e relacionadas entre si e coordenadas com o objetivo de que o conjunto das tarefas executadas pelas partes possa alcançar os objetivos organizacionais (STONER; FREEMAN, 1995, p.230). 
Hampton (1981) descreve que os principais benefícios de uma estrutura organizacional são os de deixar claro de quem são as responsabilidades e a autoridade, facilitar a comunicação entre supervisores e subordinados, melhorar o processo de tomada de decisão e diferenciar os vários tipos de atividades existentes na organização.

No sentido de se poder visualizar uma estrutura organizacional, ou seja, como as pessoas são agrupadas quando realizam tarefas comuns, a relação de dependência entre os grupos e a forma como os grupos são coordenados, é utilizado como representação simbólica o diagrama de estruturas, também conhecido como organograma (SIMERAY, 1976; STONER; FREEMAN, 1995).

$\mathrm{Na}$ literatura existem vários tipos de estrutura organizacional (HAMPTON, 1981; CERTO; PETER, 1993; MAXIMIANO, 1995; STONER e FREEMAN, 1995). As mais conhecidas são: a funcional, a territorial, a por produto, a por cliente, a por projeto e a matricial.

Independente do tipo de estrutura organizacional, para alcançar os objetivos estabelecidos por uma organização é necessário administrá-la. Segundo Stoner (1995, p.5), "a administração é o processo de planejar, organizar, liderar e controlar os esforços realizados pelos membros da organização e o uso de todos os outros recursos organizacionais".

Essas atividades relativas à administração compete exclusivamente aos dirigentes ou gerentes que são agrupados em níveis de administração. Segundo Maximiano (1995), existem três categorias. São elas:

Alta Administração, também conhecida como nível estratégico - esse nível é formado pelos executivos que possuem o poder de definir prioridades, estratégias, objetivos e metas a serem alcançados, além de avaliar o ambiente externo identificando ameaças e oportunidades; Média Gerência, também conhecida como nível tático-esse nível é responsável pela coordenação das partes da organização e pela transformação dos objetivos estabelecidos pelo nível estratégico em resultados. Supervisores de primeira linha, também conhecidos por nível operacional-esse nível concentra as chefias que ora estão administrando os funcionários responsáveis pela execução das tarefas operacionais, ora estão desenvolvendo essas tarefas.

Segundo Ribeiro (2003), no nível estratégico, as decisões geram atos cujo efeito é duradouro e mais difícil de reverter, são provenientes do planejamento de longo prazo, conhecido como Planejamento Estratégico. Neste nível atua a alta administração da organização que abrange o presidente, os diretores e os acionistas. Aqui a informação é tratada no seu nível mais macro, contemplando a empresa como um todo, tanto no aspecto interno como externo.

No nível tático, conforme o autor, as decisões ocorrem nos escalões intermediários e geram atos de efeito a prazo mais curto, porém, de menos impacto no funcionamento estratégico da empresa. Neste nível estão os gestores de nível médio: as gerências, chefias, coordenações e supervisões da empresa. Normalmente a informação retrata o que ocorre no âmbito departamental ou setorial.

No nível operacional, o autor afirma que as decisões visam alcançar os padrões de funcionamento pré-estabelecidos, com controles do detalhe ou do planejamento operacional. Neste nível encontra-se o corpo técnico da empresa: engenheiros, assistentes e auxiliares. Nesse caso, a informação é tratada em um nível mais detalhado de modo a contemplar dados necessários para a execução de uma tarefa ou atividade.

Como pode ser percebido, qualquer que seja o nível organizacional que as pessoas trabalhem ou administrem, para que as suas atividades sejam desempenhadas com eficiência e eficácia de modo que a organização cumpra seus objetivos, é fundamental a existência de informação. 
I N F O R M A Ç Ã O E M PRESARIA L

A informação é um recurso estratégico para que as organizações, enquanto sistemas abertos, mantenham o equilíbrio no funcionamento de seu ambiente interno, bem como na relação dinâmica de troca com o seu ambiente externo. Nos estudos sobre informação é possível observar que o termo apresenta inúmeras definições, não excludentes, porém sem um consenso na sua formulação. Tal fato é ressaltado nas palavras de Fernández-Molina quando diz que

São muito numerosas as definições atribuídas à informação na intenção de distingui-la de outros conceitos similares tais como dados, inteligência, mensagens, entendimento, signos ou conhecimento, mas em termos gerais tais tentativas têm sido pouco satisfatórias (FERNÁNDEZ-MOLINA, 1994, p.320).

A afirmação do autor ainda é uma realidade nos dias de hoje e isso provavelmente acontece pelo fato da informação ser utilizada para expressar significados distintos como: informação como processo (ato de informar), informação como conhecimento (conteúdo da mensagem) e informação como coisa (sinais, avisos, textos, etc.) (BUCKLAND, 1991).

A busca de definições para distinguir conceitos similares à informação também se insere no contexto das instituições em geral, uma vez que no desenvolvimento de suas atividades torna-se comum o uso de terminologias como dado, informação, conhecimento e sabedoria. Assim, no uso dos termos para fins administrativos e aplicações em sistemas de informações, define-se:

- Dado como "qualquer elemento identificado em sua forma bruta que, por si só, não conduz a uma compreensão de determinado fato ou situação" (OLIVEIRA, 2001, p.36). Observa-se, por esta definição, que qualquer informação ainda não contextualizada dentro de um determinado fato que possibilite a relação desta com outras variáveis recebe a denominação de dado.

Assim, considerando a existência de um sistema informatizado de informações nas instituições, essa forma de entendimento deve-se ao uso técnico do termo na Informática, que considera como dados as informações que são introduzidas nos sistemas, contribuindo para a expressão processamento de dados (CASSARRO, 2001).

- Informação como "[...] o dado trabalhado que permite ao executivo tomar decisões" (OLIVEIRA, 2001, p.36).No contexto deste entendimento aplicável às instituições, observa-se que o termo informação é atribuído ao dado já contextualizado e combinado com outras variáveis, permitindo a leitura de uma determinada situação a fim de subsidiar uma tomada de decisão.

No âmbito das instituições, a informação ganha diferentes denominações a fim de diferencia-las quanto ao seu ambiente de origem, sua formatação, seu uso/aplicação. Dessa forma, identifica-se a seguinte classificação² :

\section{Quanto ao ambiente de origem}

- Informação Interna: são as informações produzidas no ambiente interno da empresa. Por exemplo: folha de pagamento; controle de estoques no almoxarifado; contas a pagar; etc.

- Informação Externa:são as informações que vêm de fora da empresa e podem ser enquadradas em dois tipos:

Aquelas que provêm das instituições públicas ou privadas com

\footnotetext{
2 Observa-se que, no universo dos termos usualmente adotados nas organizações, que uma mesma informação pode se inserir em mais de uma classificação terminológica.
} 
as quais a empresa mantém contatos ou realiza negócios. Por exemplo: uma nota fiscal, emitida por um fornecedor e que ingressa na empresa acompanhando as mercadorias compradas; um "boleto" (aviso) bancário, comunicando o vencimento de um título de responsabilidade da empresa (gerado a partir de alguma compra ou contratação de serviços, por exemplo); uma guia para recolhimento de determinado imposto, provinda de uma entidade pública municipal, estadual ou federal; etc. (CASSARRO, 2001, p.45).

Aquelas que a empresa busca no mercado, de modo a conhecer o cenário atual em que opera $\mathrm{e}, \mathrm{a}$ partir deste conhecimento, ser capaz de desenvolver cenários futuros alternativos. Por exemplo: índices de participação dos principais fornecedores de determinado produto, em determinado mercado; dados econômicofinanceiros; comportamento dos consumidores; atitudes e políticas da concorrência; segmentação da comunidade (por exemplo: por idade, nível cultural, classe social, etc.) (CASSARRO, 2001, p.46).

\section{Quanto à formatação}

- Informação Estruturada:é a informação codificada, sistematizada, dentro de uma estrutura pré-estabelecida. Este tipo de informação, geralmente, é apresentado em combinação com outras variáveis a fim de permitir a leitura de uma determinada situação. Por exemplo: informações referentes à venda de um determinado produto em um dado mês do ano, possível de ser comparado ao mesmo período dos anos anteriores.
- Informação Não Estruturada: é a informação não contextualizada, que por si só não contribui para a leitura de uma determinada situação, também conhecida como dado. Por exemplo: a simples apresentação da quantidade de venda de um determinado produto, sem qualquer relação com o mês e/ou ano.

\section{Quanto ao uso/aplicação}

- Informação Estratégica: entende-se como tal aquelas informações disponibilizadas para o nível estratégico das instituições, normalmente responsável em delinear as estratégias competitivas da empresa. Esse tipo de informação possui características macro, contemplando a empresa na sua totalidade, ou seja, consideram a interação das informações do ambiente interno com aquelas provenientes do ambiente externo, como as informações sobre mercado, demográficas, políticas, econômicas, tecnológicas, sobre concorrentes atuais e potenciais etc. (DRUCKER, 1995). Por exemplo: valor do faturamento com contas a pagar; receita da empresa versus receita do concorrente etc. (REZENDE; ABREU, 2000).

- Informações Transacionais: são as informações referentes à operacionalização e controle das atividades imprescindíveis ao funcionamento harmônico da instituição, subsidiando a tomada de decisão do corpo técnico das unidades organizacionais. Por exemplo: faturamento; contabilidade fiscal; folha de pagamento; planejamento e controle de produção etc. (REZENDE; ABREU, 2000).

Conhecimento como "[...] a informação estruturada que tem valor para uma organização" (CHIAVENATTO, 2000, p.681). Embora, assim como a informação, também não haja uma uniformização conceitual do termo, observa-se que esta forma de entendimento apresentada pelo autor refere-se ao conhecimento possível de ser articulado em uma instituição, sob o enfoque de interesses que contribuam para o desenvolvimento de suas atividades. 
Para um entendimento mais claro do conceito apresentado pelo autor, torna-se importante observar que as discussões apresentadas nos estudos aplicados às organizações procuram distinguir, principalmente, dois tipos de conhecimento: o tácito e o explícito.

O conhecimento explícito, ou codificado, refere-se ao conhecimento que é transmissível em linguagem formal, sistemática, enquanto o conhecimento tácito possui uma qualidade pessoal, o que o faz mais difícil de formalizar e comunicar (OLIVEIRA JR., 2001, p.133).

Sob o ponto de vista epistemológico, o conhecimento é considerado como algo que acontece na mente do indivíduo e como tal apresenta-se como "[...] um caminho subjetivo e diferenciado para cada indivíduo" (BARRETO, 2002, p.68). Porém, apesar deste entendimento, observa-se que, no contexto das instituições, a preocupação de se distinguir o conhecimento em tácito (não sistematizado) e explícito (já sistematizado) dá-se pela crença de que, apesar de individual, o conhecimento tácito é passível de ser codificado, sistematizado, e com essa distinção torna-se possível determinar o conhecimento que já se encontra sob seu domínio e aquele que deve ser explorado, compartilhado, a fim de subsidiar suas atividades.

Apesar da similaridade conceitual sobre os termos - informação e conhecimento, por vezes apresentados como sinônimos nos dicionários, estes podem ser claramente diferenciados sob três aspectos importantes:

- enquanto o conhecimento é estruturado, coerente e frequentemente universal, a informação é atomizada, fragmentada e particular;

- enquanto o conhecimento é de duração significativa, a informação é temporária, transitória, talvez mesmo efêmera;
- enquanto o conhecimento é um estoque, a informação é um fluxo de mensagem (CINTRA et al., 2002, p.20).

\section{TECNOLOG IAS E SISTEMAS DE IN F O R M A Ç Ã O}

Segundo Boff e Antunes (1999), "Tlé um conjunto de recursos não humanos (hardware ou software) dedicados ao armazenamento, processamento e comunicação de informações e o modo como os recursos são organizados em um sistema capaz de realizar um conjunto de tarefas".

Alavi et al. (1995) citam que "Tl é a tecnologia que contempla as Áreas de Informação e de Comunicação".

Para Lucas Jr. e Olson (1994, p.156) "TI refere-se ao hardware, software, pessoal e dados empregados na produção responsável pela disseminação e utilização de informações em uma organização".

Portanto, é possível definir TI como o conjunto de recursos existentes e disponíveis em uma organização através dos quais se pode processar, armazenar, recuperar e disseminar informações. Quando nessa definição de TI é citado conjunto de recursos, devem ser entendidos dois tipos:

- Recursos computacionais: englobam os computadores e seus periféricos (hardware) que podem processar, armazenar e recuperar as informações existentes em uma organização e os programas e aplicações, também conhecidos como Sistemas de Informação (SI), responsáveis pelo processamento, armazenamento, e recuperação das informações;

- Recursos de Comunicação: são constituídos por todo e qualquer equipamento ou programa que auxilie na transmissão das informações para outro recurso computacional local ou remoto. Por exemplo, as redes locais e as redes remotas, os softwares responsáveis pela 
comunicação de dados, os roteadores, as antenas de transmissão de sinais analógicos ou digitais e outros.

A partir da definição de TI, é possível conceituar SI como sistemas que permitem coletar, armazenar, processar, recuperar e disseminar informações. Eles são hoje, quase sem exceção, baseados no computador e apoiam as funções operacionais, gerenciais e de tomada de decisão existentes na organização.

No contexto desse trabalho, a seguir serão apresentados alguns tipos de SI que serão úteis para o fornecimento de informações, dependendo de cada tipo descrito anteriormente, aos vários níveis organizacionais.

\section{SISTEM A S DE IN F O R M A ÇÃ O TRA NSA CIO N A IS (SIT)}

O processo inicial de informatização de qualquer organização é baseado fundamentalmente no desenvolvimento e na implantação de SIT (também chamados de operacionais). Esses SI são necessários para o controle operacional das organizações (TOM, 1991).

As principais funções e características desses sistemas são (FALSARELLA, 2001): coletar, via digitação, os dados existentes nos documentos operacionais das organizações, validando-os; armazenar esses dados em meio magnético; ordenar ou indexar esses dados, de modo a facilitar o acesso a eles; permitir consultas, online ou em batch, aos dados, detalhados ou agregados, que facilitem retratar diferentes aspectos das operações; gerar relatórios que possam ser usados online e distribuídos a outras pessoas que não os usuários diretos dos SI.

Sistemas que armazenam e permitem recuperar as transações de faturamento ou de contas a pagar, são exemplos de Sistemas de Informação Transacionais.

\section{SISTEM A S DE IN F O R M A ÇÃ O G EREN CIA IS (SIG)}

A evolução natural da informatização das organizações, após a implantação dos SIT, é o desenvolvimento de sistemas que forneçam informações integradas e sumarizadas que tenham capacidade de prover material para análise, planejamento e suporte à decisão (DAVIS; OLSON 1985). Esses SI que possibilitam a gerentes de médio escalão visualizar o desempenho de seu departamento e mesmo da organização como um todo, são conhecidos por Sistemas de Informação Gerenciais.

As principais funções e características desses sistemas são (FALSARELLA, 2001): integrar dados de diversas aplicações e transformá-los em informação; fornecer informações para o planejamento operacional, tático e até mesmo estratégico da organização; suprir gerentes com informações para que eles possam comparar o desempenho atual da organização com o que foi planejado; produzir relatórios que auxiliem os gerentes a tomarem decisões.

Um SI que consiga extrair das bases de dados transacionais o montante do faturamento efetuado no mês e a previsão dos próximos meses em relação as contas pagas no mês e as previstas, é um bom exemplo de Sistema de Informação Gerencial.

\section{SISTEMAS DE APOIO À DE CISÃ O (SAD)}

Os SIG descritos anteriormente podem ter funções que forneçam informações para tomada de decisão. No entanto, SAD são sistemas que não só fornecem informações para apoio à tomada de decisão, mas que contribuem para o processo de tomada de decisão.

As principais características dos SAD são: possibilidade de desenvolvimento rápido, com a participação ativa do usuário em todo o processo; facilidade para incorporar as novas 
ferramentas de apoio à decisão, os novos aplicativos e novas informações; flexibilidade na busca e manipulação das informações (BURCH; GRUDNITSKI, 1989); individualização e orientação para a pessoa que decide, com flexibilidade de adaptação ao estilo pessoal de tomada de decisão do usuário; real pertinência ao processo de tomada de decisão, ajudando o usuário a decidir através de subsídios relevantes; usabilidade, ou seja, facilidade para que o usuário o entenda, use e modifique de forma interativa (AWAD, 1988).

\section{SISTEM AS DE IN F OR M A ÇÃ O PARA EXECUTIVOS (SIE)}

Com base nos dados existentes nos SIT, nas informações disponíveis nos SIG e em informações coletadas de fontes externas à organização, podemos construir SI dirigidos para a alta gerência. Esses sistemas que abastecem a alta gerência de informações são geralmente chamados Sistemas de Informação para Executivos (WATSON et al., 1992). Segundo Lucas Jr. (1990), um SIE não tem maiores diferenças conceituais em relação a um SAD. O que o diferencia é, em geral, a interface com o usuário, que deve permitir que um executivo o utilize com facilidade.

As principais funções e características desses sistemas são (FALSARELLA, 2001): gerar mapas, gráficos e dados que possam ser submetidos a análise estatística para suprir os executivos com informações comparativas, fáceis de entender; fornecer dados detalhados sobre passado, presente e tendências futuras das unidades de negócios em relação ao mercado para auxiliar o processo de planejamento e de controle da organização; possibilitar a análise das informações obtidas; permitir que o executivo se comunique com o mundo interno e externo através de interfaces amigáveis (correio eletrônico, tele-conferência e outros.) que sejam flexíveis a ponto de se ajustarem ao seu estilo pessoal; oferecer, ao executivo, ferramentas de organização pessoal (calendários, agendas eletrônicas etc.) e de gerenciamento de projetos, tarefas e pessoas.

Um bom exemplo de Sistema de Informação para Executivos seria representar as projeções do exemplo anterior por meio de gráficos, agregando a essa representação, informações de mercado, como por exemplo, previsão de crescimento do setor, variação esperada da taxa inflacionária, entre outros.

\section{SISTEM AS DE GESTÃ O E M PRESARIA L (SGE)}

Disponíveis a partir da década de 70 , esses SI surgiram para atender a complexidade da administração de grandes organizações. Eles são constituídos por vários SIT desenvolvidos em uma mesma plataforma, ou seja, que utilizam a mesma linguagem de programação e um Sistema Gerenciador de Banco de Dados (SGBD) único. Nesse tipo de SI, podem existir alguns módulos que forneçam informações gerenciais e de apoio a decisão.

As principais funções e características desses sistemas são: integrar aplicações que coletem as informações transacionais existentes em todas as áreas operacionais da organização; permitir modularidade de modo que cada aplicação possa ser implantada independentemente das demais; possuir flexibilidade para reconfiguração do ambiente de acordo com as necessidades do usuário; fornecer, através de ferramentas orientadas para inteligência de negócios, informações para apoio ao processo de tomada de decisão.

Procurando exemplificar esse tipo de SI, quando uma transação de venda é efetuada, automaticamente o Sistema de Faturamento é acionado, gerando a transação de pagamento de comissões aos vendedores diretamente no Sistema de Contas a Pagar. Assim, o início de uma transação desencadeia, pelo fato dos SI 
estarem integrados, uma séria de outras transações decorrentes da transação inicial.

\section{IN TELIGÊ NCIA DE NEG Ó CIOS}

Um conceito cada vez mais utilizado nas organizações é o de Inteligência, que é entendido como o conjunto de Aplicações (comprometimentos) que, em um determinado contexto, permite a tomada de decisão. Assim, muito mais do que a simples reunião de informações disponíveis, a inteligência, em uma instituição, requer que a informação seja estruturada dentro de uma filosofia "suficiente-significativa" para subsidiar as operações relativas às decisões (FULD, 1994).

Assim, como suporte à realização e otimização da prática da inteligência nas instituições é que se estabelece a Inteligência de Negócios compreendida como ambientes computacionais integrados que permitem extrair de bases de dados informações de negócios e delas desenvolver análises, trabalhar com hipóteses, procurar relações de causa e efeito, entre outras aplicações, para auxiliar no processo decisório (ADELMAN et al., 2002). Neste tipo de aplicação, entende-se por processo decisório o suporte à decisão dos níveis estratégicos, táticos e operacionais.

As principais funções e características desses sistemas são: permitir a integração de informações transacionais e apresentá-las concentradas ou não por meio de cubos multidimensionais de modo que a organização possa ser vista de várias maneiras (KURZ; TJOA, 1997); possibilitar análise de contextos; extrair informações detalhadas ou aglutinadas, dependendo do nível de análise a ser feito; possibilitar análise do relacionamento existente entre informações diferentes; permitir a realização de simulações e a procura de relações de causa e efeito.

Procurando utilizar como referência os exemplos anteriores, um sistema de inteligência de negócios poderia ser exemplificado se fosse possível apresentar, de forma agregada ou detalhada, a evolução da relação existente entre o faturamento e as contas a pagar ao longo do tempo. Pode ser inserida, neste mesmo exemplo, a possibilidade de visualização em meses que apresentem informações distorcidas ou não esperadas, os clientes que deixaram de comprar. Com essas informações, o executivo ou gerente poderá entender o motivo de eventuais desvios.

\section{LATÊ NCIA ZERO}

O uso da informação e o a adoção das tecnologias e sistemas de informação representam a otimização do processo decisório e o bom andamento das operações de uma instituição. Este entendimento faz parte de um processo compreendido nas instituições como a gestão da informação, que visa monitoramento constante do seu ambiente interno e externo. Porém, observa-se que uma gestão eficaz e eficiente não pode ser alcançada apenas com a coleta, organização e disseminação de informações através do uso de sistemas de informações. Para tanto, torna-se necessário que se estabeleçam procedimentos metodológicos, que viabilizem essa otimização na gestão da informação, como o sugerido pela latência zero.

Latência é o período de inatividade entre um estímulo e a resposta por ele provocada.

Monitoramento de atividades de negócios, termo proveniente do inglês Business Activity Monitoring (BAM) criado pelo Gartner Group, é um conceito que procura prover informações e/ ou indicadores críticos em tempo real, para diminuir o tempo de resposta das atividades de negócios, de modo que seja possível melhorar o gerenciamento de problemas, reduzir tempos de resposta e aumentar a produtividade (CATEGORIC..., 2002).

Dentro deste contexto surge o conceito de "Latência Zero" significando que, após o 
recebimento de um estímulo - provocado por um evento, por uma pessoa ou departamento - não houve qualquer demora na sua resposta, ou seja, uma ação foi executada imediatamente.

Assim, um SI que possibilite encaminhar ao usuário informações imediatamente à ocorrência de um evento, como se propõe o BAM, leva a organização ao estado conhecido por "Latência Zero", pois permite ao tomador de decisão realizar ações quase no mesmo momento do seu surgimento.

Para que o conceito de Latência Zero seja aplicado nas organizações, alguns elementos podem ser considerados. São eles:

1) Sistemas de Informação que possuam "observadores" que monitoram as informações do ambiente organizacional e forneçam estímulos sobre mudanças de comportamentos previamente estabelecidas por meio de indicadores.

2) Níveis gerenciais que devem receber os estímulos provocados pelas mudanças de comportamento e, a partir deles, tomar decisões.

3) Repositórios de informação que possam indicar mudanças de comportamento e serem, portanto, monitorados pelos observadores.

O conjunto de elementos descritos acima (Figura 1), pode ser chamado de Ambiente de Observação.

O repositório de informação contém informações internas ou externas à organização, estruturadas ou não-estruturadas, transacionais ou estratégicas. Essas informações são constantemente e continuamente mantidas e consultadas pelos vários tipos de SI existentes (transacionais, gerencias, de apoio à decisão, de informação ao executivo, de gestão empresarial ou de inteligência de negócios).

Cada tipo de SI pode, pensando-se na aplicação do conceito de Latência Zero, possuir entidades chamadas nesse trabalho de observadores, que têm a finalidade de monitorar

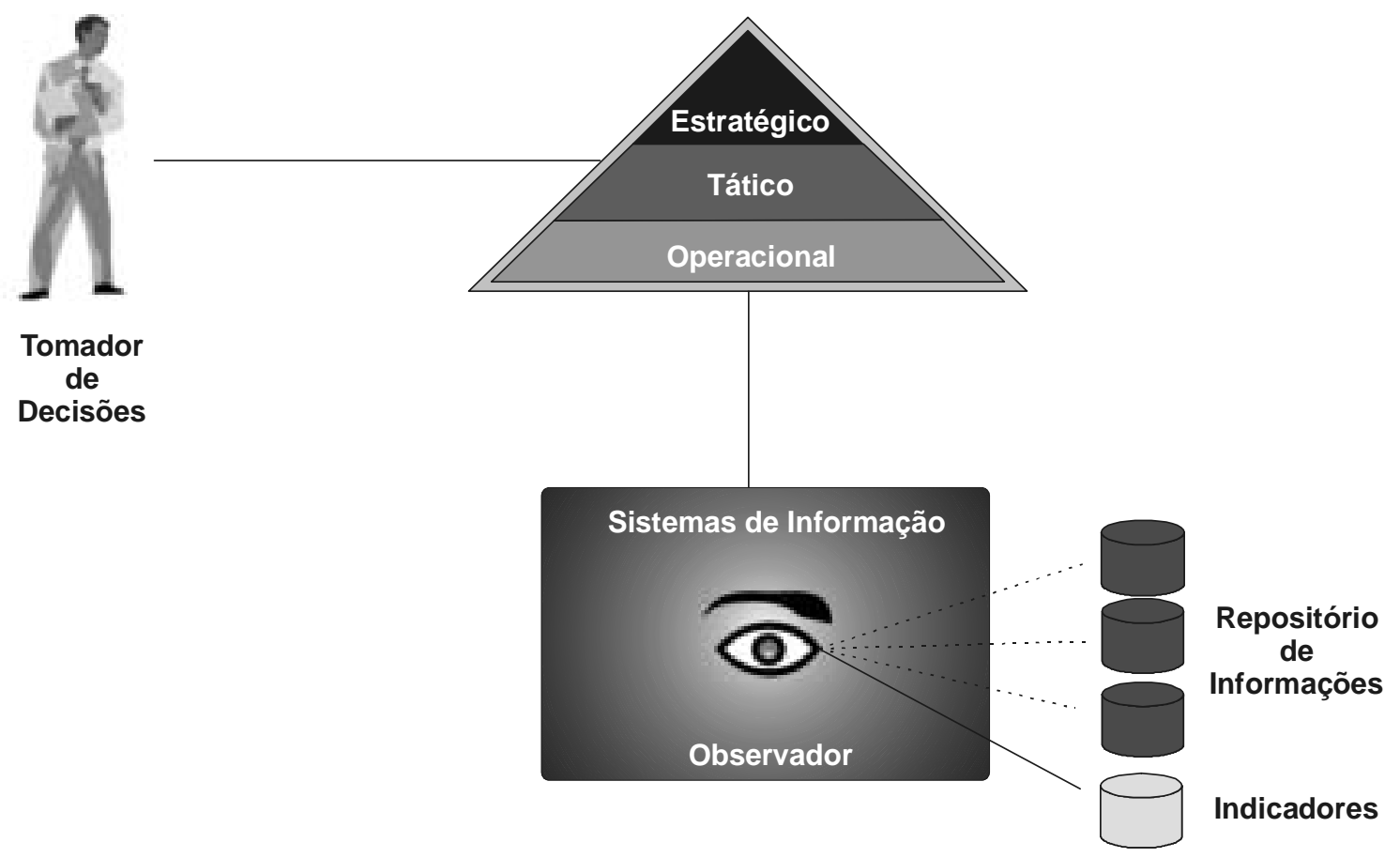

Figura 1. Ambiente de Observação. 
os repositórios de informação à procura de estímulos que reproduzam mudanças de comportamentos pré-estabelecidos. Esses observadores, na realidade, consultam indicadores de desempenho que permitem compará-los com o ambiente informacional e, por meio dessa comparação, identificar mudanças comportamentais. Quando mudanças ocorrem, o observador envia um estímulo ao usuário responsável pela tomada de decisão.

Um conceito que pode ser utilizado para a criação de indicadores é o Balanced Scorecard (BSC). Segundo Miranda (2001), Balanced Scorecard é um sistema de gerenciamento estratégico que permite monitorar as estratégias de uma organização por meio de mecanismos de mensuração permitindo visualizar passo a passo a estratégia em andamento. Nesse sentido, é necessário criar indicadores de desempenho que possam monitorar resultados ou desvios.

O Balanced Scorecard possui quatro perspectivas para aferição. São elas:

1. Financeira - avalia o lucro a ser aferido (instituições privadas) ou a eficiência do custo em relação ao valor agregado ao contribuinte (instituições públicas) - rentabilidade, crescimento, cumprimento de metas para com os acionistas, etc.;

2. Cliente - avalia a prestação de serviços ao cliente relacionado à sua satisfação (fidelidade, retenção, capitação de novos clientes, etc.);
3. Processos internos - avalia o que os processos-chave do negócio e de suporte a eles podem ser melhorados em relação ao sucesso financeiro e satisfação dos clientes que eles podem trazer (tempo de entrega, cumprimento de prazos e qualidade na produção, retrabalho, etc.);

4. Aprendizagem e crescimento - avalia as habilidades e qualidades dos funcionários no sentido de melhora continuada (satisfação, retenção e participação dos funcionários, etc.).

O ambiente de observação proposto pode possuir vários níveis de observação cada um relacionado a um dos níveis gerenciais (estratégico, tático ou operacional). Neste sentido, cada nível gerencial pode agregar tipos de informação e Sistemas de Informação diferentes (Quadro 1).

Pelas características dessas referências, descritas anteriormente para o nível operacional, o ambiente de observação pode estar associado aos sistemas de informação transacionais, devendo, portanto, monitorar informações internas e estruturadas.

Para o nível tático, o ambiente de observação poderá possuir observadores inseridos em sistemas de informação gerencial, sistemas de apoio à decisão e nos sistemas de gestão empresarial. As informações monitoradas são normalmente internas, estruturadas e nãoestruturadas.

Já o nível estratégico, que se preocupa em trazer vantagens competitivas para a

Quadro 1. Relação Níveis Gerenciais, Informação e Sistemas de Informação.

\begin{tabular}{lll}
\hline Tipos de Informação & Níveis Gerenciais & Tecnologia e Sistemas de informação \\
$\begin{array}{l}\text { Externa, interna, estruturada e não } \\
\text { estruturada }\end{array}$ & Estratégico & SAD, EIS, Inteligência de negócios \\
Interna, estruturada e não estruturada & Tático & SAD, SIG e sistema de gestão empresarial \\
Interna e estruturada & Operacional & Transacional \\
\hline
\end{tabular}


organização, pode possuir observadores muito complexos inseridos em sistemas de inteligência de negócios, de informação para executivos e de apoio à decisão. A complexidade está relacionada ao tipo de informação analisada: menos estruturada, pouco interna, mais externa e não-estruturada.

Procurando ilustrar, alguns exemplos de observação serão descritos a seguir:

O ambiente de observação possui como referencial o indicador "número mínimo de sapatos vendidos mensalmente". Um observador poderia acompanhar o faturamento e fazer projeções de vendas de modo a enviar um estímulo ao gerente de vendas todas as vezes que o projetado for inferior ao número mínimo de vendas mensal.

O ambiente de observação possui, como referencial, indicadores que traduzem se uma organização que produz bens de consumo deve investir na ampliação da produção ou no mercado financeiro. Um observador, bastante "inteligente" poderia acompanhar os níveis de faturamento, a capacidade de produção, o preço da matéria prima, a margem de lucratividade, a variação do dólar, os juros pagos pelo mercado financeiro, entre outros e enviar estímulos de modo que um alto executivo possa decidir se deve ampliar a produção ou investir no mercado financeiro.

\section{O N SIDERAÇÕ ES FIN A IS}

$\mathrm{Na}$ aplicação da Latência Zero, a determinação dos indicadores é parte essencial do processo, uma vez que eles representam os contextos a serem observados e identificam os pontos críticos inerentes a este monitoramento. Porém, ressalta-se que o conceito de Latência Zero, aplicado a cada nível gerencial, possuindo observador mais ou menos inteligente (de acordo com a sua complexidade), só será efetivamente colocado em prática quando a resposta ao estímulo for efetivamente iniciada. Portanto, quanto melhor e mais rápido for fornecido subsídios para o processo de tomada de decisão, maior o poder de uma organização conseguir vantagem competitiva.

\section{RE FER Ê N C I A S}

ADELMAN, S.; MOSS, L.; BARBUSINSKI, L. I found several definitions of BI. DM Review, agosto, 2002. Available from: <http://www.dmreview.com/master. cfm? NavID $=55 \& E d I D=5700>$. Acess: 11 nov. 2003.

ALAVI, M. et al. Using IT to reengineer business education: an exploratory investigation of collaborative telelearning. MIS Quarterly, Minneapolis, v.19, n.3, p.293-312, 1995.

ANSOFF, H.I.; McDONNEL, E.J. Implantando a administração estratégica. São Paulo: Atlas, 1993. p.25-34.

AWAD, E.M. Management information systems: concepts, structure and applications. Menlo Park: Benjamin/Cummings, 1988. Paginação irregular.

BARRETO, A.A. A condição da informação. São Paulo em Perspectiva, São Paulo, v.16, n.3, p.67-74, 2002.
BOFF, L.H.; ANTUNES JR., J.A.V. Combinando inovações organizacionais e tecnológicas: um modelo para conduzir processos de reestruturação. READ - Revista Eletrônica de Administração, Porto Alegre, v.1, n.1, 1999. Disponível em: <http:// read.adm.ufrgs.br/read01/artigo/boff.htm\#boff>. Acesso em: 10 set. 2000.

BRESCIANI FILHO, E.; D'OTTAVIANO, I.M.L. Conceitos básicos de sistêmica: auto-organização. Estudos Interdisciplinares, Campinas, v.30, p.283306, 2000.

BUCKLAND, M.K. Information as thing. Journal of the American Society for Information Science, v.42, n.5, p.351-360, 1991.

BURCH, J.G.; GRUDNITSKI, G. Information systems: theory and practice. 5.ed. New York: John Wiley \& Sons, 1989. 921p. 
CASSARRO, A.C. Sistemas de informações para tomada de decisões. São Paulo: Pioneira Thomson Learnig, 2001. 129p.

CATEGORIC Software, 2002. Disponível em: <http:/ /www.categoric.com.br>. Acesso em: 15 mar. 2003.

CERTO, S.C.; PETER, J.P. Administração estratégica. São Paulo: Makron Books, 1993. 469p.

CHIAVENATO, I. Introdução à teoria geral da administração. 6.ed. Rio de Janeiro: Campus, 2000. p.655-695.

CINTRA, A.M.M.; TÁLAMO, M.F.G.M.; LARA, M.L.G.; KOBASHI, N.Y. Para entender as linguagens documentárias. 2.ed. São Paulo: Polis, 2002. 96p.

DAVIS, G.B.; OLSON, M.H. Management information systems. 2.ed. New York: McGraw-Hill, 1985. 693p.

DRUCKER, P.F. Administrando em tempos de grandes mudanças. São Paulo: Pioneira, 1995.

FALSARELLA, O.M. Modelo de análise e planejamento de tecnologia de informação para instituições de ensino superior. 2001. 184f. Tese (Doutorado em Engenharia Mecânica) - Engenharia Mecânica, Universidade Estadual de Campinas, Campinas, 2001.

FERNÁNDEZ-MOLINA, J.C. Enfoques objetivo y subjetivo Del concepto de información. Revista Española de Documentación Científica, v.17, n.3, p.320-330, 1994.

FULD, L.M. The new competitor intelligence: the complete resource for finding, analyzing, and using information about your competitors. New York: John Wiley \& Sons, 1994. 482p.

HAMPTON, D.R. Administração contemporânea: teoria, prática e casos. 3.ed. São Paulo: McGraw-Hill, 1981. 370p.

KARAPETROVIC, S. et al. To regain competitiveness higher education must adopt industrial techniques. Quality Progress, v.32, n.5, p.87-95, 1999.

KURZ, A.; TJOA, A.M., Data Warehousing within intranet: prototype of a web-based executive information systems. In: INTERNATIONAL WORKSHOP ON DATABASE AND EXPERT SYSTEMS APPLICATIONS, 8., 1997, Dexa.
Proceedings... Toulouse: IEEE Computer Society, 1997.

LUCAS JR., H.C. Information systems concepts for management. 4.ed. New York: McGraw-Hill,1990. 530p.

LUCAS JR. H.C.; OLSON, M. The impact of information technology on organizational flexibility. Journal of organizational computing, Norwood, v.4, n.2, p.155-176, 1994.

MACEDO, J.N. A gestão dos sistemas de saúde e a cultura organizacional: cultura organizacional e a gestão descentralizada do SUSU. READ - Revista eletrônica de administração, Porto Alegre, v.2, n.3, 1996. Disponível em: <http://read.adm.ufrgs.br/ read04/artigo/sus.htm>. Acesso em: 12 out. 1999.

MAIA, H.H.R.P.; SOUZA, J. Proposta de um modelo ideal de atuação empresarial com enfoque na controladoria. In: CONGRESSO BRASILEIRO DE CUSTOS, 6., 1999, São Paulo. Anais... São Paulo: USP, 1999. Disponível em: <http://www.gecon.com. br/Artigos/T053por.htm>. Acesso em: 27 jul. 1999.

MAXIMIANO, A.C.A. Introdução à administração. 4.ed. São Paulo: Atlas, 1995. 476p.

MEIRELLES, F.S. Informática: novas aplicações com microcomputadores. São Paulo: Makron Books, 1994. p.3-20.

MIRANDA, R.C.R. Balanced Scorecard. In: TARAPANOFF, K. (Org.). Inteligência organizacional e competitiva. Brasília: Universidade de Brasília, 2001. p.227-239.

OLIVEIRA, D.P.R. Sistemas de informações gerenciais: estratégicas táticas operacionais. São Paulo: Atlas, 2001. 285p.

OLIVEIRA JR., M.M. Competências essenciais e conhecimento na empresa. In: FLEURY, M.T.L.; OLIVEIRA JR., M.M. (Org.). Gestão estratégica do conhecimento. São Paulo: Atlas, 2001. p.121-156.

PORTER, M.E. Estratégia competitiva: técnicas para análise de indústrias e da concorrência. Rio de Janeiro: Campus, 1991. 362p.

REZENDE, D.A.; ABREU, A.F. Tecnologia da informação aplicada a sistemas de informação empresariais: o papel estratégico da informação e dos sistemas de informação nas empresas. São Paulo: Atlas, 2000. 311p. 
RIBEIRO, P.R. Uma forma de integrar: planejamento estratégico; balanced scorecard e sistemas de informação, resultando em um modelo de gestão empresarial. 2003. 109f. Dissertação (Mestrado em Informática) - Centro de Ciências Exatas, Ambientais e de Tecnologias, Pontifícia Universidade Católica de Campinas, Campinas, 2003.

SIMERAY, J.P. A estrutura da empresa. São Paulo: Livros Técnicos e Científicos, 1976. 246p.
STONER, J.A.F.; FREEMAN, R.E. Administração. 5.ed. Rio de Janeiro: Prentice-Hall do Brasil, 1995. 533p.

TOM, P.L. Managing information as a corporate resource. 2.ed. New York: Harper Collings Publishers, 1991. 464p.

WATSON, H.; RAINER, R.K.; HOUDESCHEL, G. Executive information systems: emergence, development and imapct. New York: John Wiley \& Sons, 1992. 357p. 